\title{
Factors influencing Janani Suraksha Yojana utilization in a northern city of India
}

\section{Sonu Goel ${ }^{1 *}$, Deepak Sharma ${ }^{2}$, Soma Rani $^{3}$}

\author{
${ }^{1}$ Department of Health Management, School of Public Health, Post Graduate Institute of Medical Education and \\ Research, Chandigarh, Punjab, India \\ ${ }^{2}$ Department of Community Medicine, GMCH, Chandigarh, Punjab, India \\ ${ }^{3}$ District Family Welfare Officer, Chandigarh, Punjab, India
}

Received: 26 November 2016

Accepted: 20 December 2016

\section{*Correspondence:}

Dr. Sonu Goel,

E-mail: sonugoel007@yahoo.co.in

Copyright: (C) the author(s), publisher and licensee Medip Academy. This is an open-access article distributed under the terms of the Creative Commons Attribution Non-Commercial License, which permits unrestricted non-commercial use, distribution, and reproduction in any medium, provided the original work is properly cited.

\begin{abstract}
Background: Janani Suraksha Yojana (JSY) was launched by Government of India with an objective of increasing institutional delivery. After years of operationalization in the Union territory of Chandigarh, no studies have documented the extent of its utilization and in-turn, effectiveness of its implementation. The aim and objectives of the study was to ascertain the extent of utilization of JSY scheme and to explore the factors influencing its uptake.

Methods: It was a community based cross-sectional mixed method concurrent study conducted from August 2012 to March 2014 in Chandigarh city. A total of 100 women residing in the catchment areas of primary and secondary level health care facilities of Chandigarh who gave birth in proceeding two years (2011 and 2012) were interviewed using a structured questionnaire and in-depth interview checklist by trained field investigators. Data analysis was done using SPSS software for windows (version 17).

Results: A total of 100 mothers were approached out of which 94 delivered in institution and 34 received JSY benefit. Logistic regression model suggested that more than 3 ANC visits by women was significantly associated with the uptake of JSY benefit $(\mathrm{OR}=17.4)$. The factors influencing decreased uptake of scheme were sub-optimal incentive, delayed payment, problem in arranging for a residence proof and lot of administrative paper work.

Conclusions: Though the JSY scheme led to high rate of institutional delivery but the monetary incentive was not availed by most of the beneficiaries. There is a need to remove the bottlenecks and thus ensure smooth delivery of cash benefits.
\end{abstract}

Keywords: IUD, IOL, Mifepristone, Pregnancy, Previous CS

\section{INTRODUCTION}

Maternal deaths are not just a matter of public health concern, but also a human rights failure. The Government of India is committed to the promotion of maternal and child health. National Rural Health Mission (NRHM), an initiative by the government of India in the year 2005 has launched various initiatives for promotion of maternal health. One such initiative is the Janani Suraksha Yojana (JSY) which aims at reducing maternal mortality by promoting institutional delivery. It is being implemented through community-level health workers (such as Accredited Social Health Activists [ASHAs]), who identify pregnant women and help them to get to a health facility. The scheme is fully sponsored by the Central Government and is implemented in all states and Union Territories (UTs) of India. ${ }^{1,2}$

Varying degrees of success of JSY scheme has been reported across various states in India. JSY has increased client-provider contact, proportion of women having ANC check-ups and institutional delivery. ${ }^{4-6}$ However, few studies have documented some issues with the 
implementation of scheme like problem in timely disbursement of cash incentive and lacking awareness about the scheme., ${ }^{7,8}$ The assessment of scheme in selected states of India concluded that a varied proportion of beneficiaries ranging from $5-44 \%$ received the cash incentive. ${ }^{9}$

JSY scheme was launched in the year 2007 in Chandigarh city. Since then, health workers are regularly mobilizing and helping the pregnant women avail cash assistance as an incentive for institutional delivery. To the best of our knowledge, no studies have been conducted to document the effectiveness of its implementation in the city and also in the neighboring states. Such studies can help in identifying the lacuna in its implementation and advocate implementation of policy to focus on the issue. With this background, a study was done to ascertain the extent of utilization of JSY scheme and to explore the factors influencing its uptake in Chandigarh city.

\section{METHODS}

It was a mixed method design using quantitative as well as qualitative methods concurrently. The study was conducted between August 2012 and March 2014 in Chandigarh city. Chandigarh has a total population of around 1.05 million spread over an area of 114 square kilometers (population density- 9,252 people per sq. km). The health infrastructure has an almost equal mix of public and private institutions. In government sector, there are tertiary care institutions (DH Govt. MultiSpecialty Hospital, Sector 16, Chandigarh, Govt. Medical College and Hospital, Sector 32, Chandigarh and Post Graduate Institute of Medical Education and Research, Sector-12), 34 dispensaries and 17 subcentres.

Sample size estimation for the quantitative part of the study was based upon $50 \%$ assumed prevalence of participants receiving JSY cash benefit, $10 \%$ precision and $10 \%$ non response rate, which comes out to be 106 participants. Ten dispensaries/subcentres in Chandigarh city were randomly selected for achieving this sample size. Trained field investigators visited the selected health institution and after taking informed consent from the Incharge, conducted a record review of antenatal cases register to list all the s probable JSY beneficiaries who delivered in the years 2011 and 2012. Subsequently a total of 11 study subjects were randomly selected from the list, thereby totaling to 110 probable beneficiaries from the study area.

A pretested semi-structured questionnaire was used to elicit the information for the quantitative part of the study. For the qualitative part, data was collected by one to one, in-depth open-ended interviews, ranging from one to one-and-a half hours in length. The interview began with a chat to establish rapport, after which study participants were asked to give their views about JSY scheme. A topic guide developed by investigators was used for probing study subjects. They were asked for the possible hurdles in getting the JSY benefit.

The quantitative data was entered and analyzed using SPSS software for windows (version 17). Basic descriptive statistics as well as tests of significance for proportions were computed. The dependent variable was women who received financial assistance (JSY benefit) whereas the independent variables included maternal age, education, caste, religion, information on birth history, gender of the child, possessing proof of belonging to Scheduled cast/Scheduled tribe/Below Poverty Line, urban or rural residence, and distance to the nearest health facility. "Beneficiary of JSY services" was defined as a pregnant woman who successfully availed cash benefit after delivering at a hospital while "Nonbeneficiary of JSY services" was one who despite delivering in hospital did not receive cash benefit. Knowledge about JSY scheme was assessed by asking "The main focus of JSY scheme is to promote safe institutional deliveries?" All those who replied affirmative were considered to have "knowledge about JSY scheme". The "early ANC visit" was considered as one if a pregnant woman started her first ANC visit within the first 12 weeks of gestation. For the qualitative data, emerging themes among the responses were coded and analyzed by the first author to generate higher order generalizations. Ethical approval was obtained from the Institute Ethics Committee of Post Graduate Institute of Medical Education and Research, Chandigarh before starting the study.

\section{RESULTS}

A total of 110 mothers were approached out of which 100 consented to be part of the study (response rate $=90.9 \%$ ). Out of 100 mothers, 94 delivered in institution and 34 received JSY cash benefit. The mean age of the mothers was 22.7 years $(\mathrm{SD}=3.3)$. Hindus $(89 \%)$ were the majority, $70 \%$ were literate and $32 \%$ belonged to the lower income group. $21(21 \%)$ women had received minimum three antenatal visits in the last pregnancy with 84 per cent of them having started their antenatal checkups in early pregnancy period (less than 12 weeks). Among the study subjects, $80 \%$ delivered in government institution and $14 \%$ in private institutions. All (100\%) had heard about JSY scheme and thus registered for benefits but merely $42 \%$ knew about its main focus of promoting safe institutional delivery.

The logistic regression model demonstrated that more than three antenatal visits was significantly associated with the dependent variable $(\mathrm{OR}=17.4)$ which signifies the fact that increased ANC visits was related to increased odds of availing JSY benefit. Study subjects aged more than 25 years had higher odds of getting JSY benefit $(\mathrm{OR}=1.27)$. Similarly those participants who resided in urban area had higher odds of getting JSY benefit. Moreover, those study subjects who had adequate knowledge about JSY (OR=4.12) and those delivering in 
government hospital $(\mathrm{OR}=1.16)$ had higher odds of getting JSY benefit. In-depth interviews with ANMs outlined their views about the beneficiaries not availing the JSY benefit. Some were of the opinion that the meager JSY amount was a de-motivating factor for seeking the benefit. Others felt that there was problem in arranging for a residence proof for migrants which is a necessary document for availing JSY benefit. Many ANMs informed that payment was not received on time despite fulfilling the eligibility criteria.

Table 1: Beneficiary level factors influencing JSY scheme utilization in Chandigarh city.

\begin{tabular}{|c|c|c|c|c|}
\hline Variables & $\mathbf{N}=\mathbf{1 0 0}$ & $\begin{array}{l}\text { Got JSY benefit } \\
\mathrm{N}=34\end{array}$ & $\begin{array}{l}\text { Did not get JSY benefit } \\
N=66\end{array}$ & $\begin{array}{l}\text { Chi square, } p \\
\text { value }\end{array}$ \\
\hline \multicolumn{5}{|c|}{ 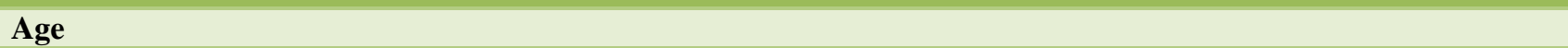 } \\
\hline up to 25 years & 74 & $29(39.2)$ & $45(60.8)$ & $3.4,0.06$ \\
\hline 26 years and above & 26 & $5(19.2)$ & $21(80.8)$ & \\
\hline Occupation & 0 & & & \\
\hline Housewife & 10 & $5(50)$ & $5(50)$ & $1.2,0.26$ \\
\hline Working & 90 & $29(32.2)$ & $61(67.8)$ & \\
\hline \multicolumn{5}{|l|}{ Education } \\
\hline Illiterate & 30 & $10(33.3)$ & $20(66.7)$ & $0.00,0.92$ \\
\hline Literate & 70 & $24(34.3)$ & $46(65.7)$ & \\
\hline \multicolumn{5}{|l|}{ Place of residence } \\
\hline Rural & 64 & $20(31.3)$ & $44(68.8)$ & $0.59,0.43$ \\
\hline Urban & 36 & $14(38.9)$ & $22(61.1)$ & \\
\hline \multicolumn{5}{|c|}{ Early ANC registration } \\
\hline Yes & 16 & $4(25)$ & $12(75)$ & $0.68,0.40$ \\
\hline No & 84 & $30(35.7)$ & $54(64.3)$ & \\
\hline \multicolumn{5}{|l|}{ Number of ANC visits } \\
\hline Up to 3 visits & 21 & $1(4.8)$ & $20(95.2)$ & $10.1,0.01$ \\
\hline More than 3 visits & 79 & $33(41.8)$ & $46(58.2)$ & \\
\hline \multicolumn{5}{|c|}{ Knowledge about JSY scheme } \\
\hline No & 58 & $18(31)$ & $40(69)$ & $0.54,0.46$ \\
\hline Yes & 42 & $16(38.1)$ & $26(61.9)$ & \\
\hline \multicolumn{5}{|c|}{ Valid documents of proof for SC/ST/BPL } \\
\hline Yes & 32 & $8(25)$ & $24(75)$ & $1.69,0.92$ \\
\hline No & 68 & $26(38.2)$ & $42(61.8)$ & \\
\hline \multicolumn{5}{|l|}{ Place of delivery } \\
\hline Private & 80 & $31(38.8)$ & $49(61.3)$ & $4.7,0.08$ \\
\hline Government Hospital & 14 & $3(21.4)$ & $11(78.6)$ & \\
\hline Home delivery & 6 & $0(0)$ & $6(100)$ & \\
\hline
\end{tabular}

In-depth interviews with the beneficiaries revealed that they had to travel many times for getting JSY money. The amount spent on such effort was almost same or even more than that credited to their account. One beneficiary told that "It is a harassment in availing JSY benefit.....it requires too much paper work.... and even if we complete all the formalities we do not get money on time...". Another beneficiary said, "We should get payment before delivery as we need it most during that time. There should be minimum paper work". Interviews with nodal officer Reproductive and Child Health looking after JSY scheme in Chandigarh revealed that as per the government instructions the payment was to be done through AADHAR based Direct Beneficiary Transfer which is a national individual identification number issued by the Unique Identification Authority of India (UDAI) on behalf of the Government of India. Due to certain technical issues in linking AADHAR to JSY payment system, the funds could not be disbursed on time. Nodal officer said that "one of the reasons about the poor uptake of JSY services was lack of staff (additional ANM). Since 2012, the staff has been increased, so as the JSY services. We have improved the documentation, and behavior change communication strategies have been stronger over time".

\section{DISCUSSION}

In the present study, the cash benefits of JSY scheme was availed by mere $34 \%$ of the respondents, despite all 
having heard about the scheme and increased awareness of the fact that it is for promoting safe institutional delivery $(42 \%)$. Difficulties while availing incentives coupled with lack of information about the scheme are the possible reason for low uptake of the cash benefit. In consonance with the findings, a study done by Vikram et al in Delhi observed that despite high awareness level a lesser proportion of beneficiaries received the cash benefit. ${ }^{10}$ Panja et al in a study in West Bengal found that just over half of the eligible women received the cash benefits. ${ }^{11}$ Lim et al. did a secondary data analysis of "District Level Household Survey (DLHS)" in India and reported a variable proportion ranging from $5-44 \%$ of women receiving cash payments from JSY after delivery. ${ }^{9}$

Table 2: Logistic regression model influencing JSY scheme utilization in Chandigarh city.

\begin{tabular}{|c|c|c|c|c|}
\hline & Odds ratio & Lower CI & Upper CI & $P$ value \\
\hline \multicolumn{5}{|l|}{ Age } \\
\hline up to 25 years & $\mathrm{R}$ & & & \\
\hline 26 years and above & 0.31 & 0.08 & 1.27 & 0.103 \\
\hline \multicolumn{5}{|l|}{ Occupation } \\
\hline Housewife & $\mathrm{R}$ & & & \\
\hline Working & 0.68 & 0.14 & 3.26 & 0.626 \\
\hline \multicolumn{5}{|l|}{ Education } \\
\hline Illiterate & $\mathrm{R}$ & & & \\
\hline Literate & 0.81 & 0.27 & 2.46 & 0.708 \\
\hline \multicolumn{5}{|l|}{ Place of residence } \\
\hline Rural & $\mathrm{R}$ & & & \\
\hline Urban & 1.28 & 0.29 & 5.78 & 0.746 \\
\hline \multicolumn{5}{|l|}{ Early ANC registration } \\
\hline Yes & $\mathrm{R}$ & & & \\
\hline No & 0.97 & 0.21 & 4.38 & 0.964 \\
\hline \multicolumn{5}{|l|}{ Number of ANC visits*" } \\
\hline Up to 3 visits & $\mathrm{R}$ & & & \\
\hline more than 3 visits & 17.44 & 1.83 & 166.60 & 0.013 \\
\hline \multicolumn{5}{|l|}{ Knowledge about JSY scheme } \\
\hline No & $\mathrm{R}$ & & & \\
\hline Yes & 4.12 & 0.94 & 18.03 & 0.06 \\
\hline \multicolumn{5}{|l|}{ Valid documents of proof for SC/ST/BPL } \\
\hline $\begin{array}{l}\text { Have proof of belonging } \\
\text { to SC/ST/BPL }\end{array}$ & $\mathrm{R}$ & & & \\
\hline Do not have proof of belonging to SC/ST/BPL & 1.61 & 0.51 & 5.08 & 0.415 \\
\hline \multicolumn{5}{|l|}{ Place of delivery } \\
\hline Private & $\mathrm{R}$ & & & \\
\hline Government Hospital & 1.16 & 0.24 & 5.77 & 0.853 \\
\hline
\end{tabular}

Lanjewar et al reported that $53 \%$ of women got the JSY benefit in Maharashtra ${ }^{12}$.Vishwanath observed that $30 \%$ of women got the JSY benefit in their study in Solapur, Maharashtra $^{13}$ while it was $294 \%$ in Haryana. ${ }^{14}$ In a study done in Orrisa done by Malini et al low acquaintance about the benefits of JSY scheme was highlighted. Also, less than half of mothers knew that the JSY scheme is for promoting institutional delivery. ${ }^{15}$ The present study observed that women having more than three ANC visits during pregnancy had higher odds of receiving JSY benefit. This finding is similar to that reported in a study done by Vikram et al. among urban population of Delhi. ${ }^{10}$ This may be due to the fact that increasing number of antenatal care visits increases the likelihood of clearing the early obstacles in enrolling for JSY benefit as the beneficiary develop rapport with the health worker. The present study inferred that the rural population lagged behind in the availing JSY benefit. This may be due to road connectivity issues or the increased time spent on travelling to centre for completing the JSY formalities and finally availing the benefit. The current study found that education status was not related with availing JSY benefit. Contrary results were observed in a study done by Vikram et al wherein more proportion of educated women availed JSY benefit. $^{10}$ 
Most of the respondents were aware - of the JSY scheme and thus registered for benefits but quite few were aware of the fact that it is for promoting institutional delivery. Similar to our finding Singh et al. carried out a study in Bihar and found that very few knew about the specifications of the scheme. ${ }^{16}$ In our study, ANMs acted as the major sources of information, the findings are in concurrence with a study by Vikram et al, whereas in the study by Singh et al, for more than half of the participants the source of information was neighbours. ${ }^{10,16}$

The findings of in-depth interviews suggested that accessing the incentive for JSY scheme were cumbersome. Numerous instances and reasons of delayed payment were cited in the study. Also, the participants expressed that the amount spent for getting JSY benefit was almost similar to the amount credited to their account. Similar finding of difficulty in obtaining cash benefit was reflected in an impact evaluation of India's JSY by Lim SS. ${ }^{9}$ Ved et al in his study on Program evaluation of the Janani Suraksha Yojna in eight empowered action group states in India observed a significant out of pocket expenses for availing JSY benefit. Some women delivered at home citing reasons like poor service quality, high costs in institutions and cultural preferences. ${ }^{17}$

In conclusion, the present study found that the JSY scheme led to high rate of institutional delivery, but the monetary incentive was not availed by most of the beneficiaries. The reason was the problem in arranging for a valid document like residence proof for opening a bank account. Apart from this there were health system hurdles like staff crunch and delay in releasing money for the scheme from the government. It is thus suggested that these bottlenecks must be removed so that beneficiaries get cash benefit on time. This will enable further uptake of the scheme by mothers. Informed consent was obtained from all individual participants included in the study.

\section{Funding: Partial funding from PGIMER under Intramural Grant \\ Conflict of interest: None declared \\ Ethical approval: The study was approved by the Institutional Ethics Committee}

\section{REFERENCES}

1. Maternal health. Available from URL http://www.mohfw.nic.in/WriteReadData/1892s/Chapter 415.pdf. Accessed on 18-5-2016.

2. Janani Suraksha Yojana . Available from URL: http://nrhm.gov.in/nrhm-components/rmnch-a/maternalhealth/janani-suraksha-yojana/background.html. Accessed on 18-5-2016.

3. Assessment of Janani Surakha jojna in Assam. Available from URL:
http://www.cortindia.in/RP\%5CRP-2007-0702.pdf. Accessed on 15-6-2016.

4. Assessment of Janani Surakha jojna in Bihar. Available from URL: http://www.cortindia.in/ RP\%5CRP-20070701.pdf. Accessed on 15-6-2016.

5. Uttekar BP, Uttekar V, Chakrawar BB, Sharma J, Shahane S. Assessment of Janani Suraksha Yojana in Uttar Pradesh. Centre for Operations Research and Training, Vadodara: UNICEF, New Delhi. 2008:33-4.

6. Kumar V, Misra SK, Kaushal SK, Gupta SC, Khan AM. A study on the effect of janani suraksha yojana on antenatal registration and institutional deliveries in the Agra district of Uttar pradesh. Indian J Public Health. 2015;59:54-7.

7. Schmidt JO, Ensor T, Hossain A, Khan S. Vouchers as demand side financing instruments for health care: a review of the Bangladesh maternal voucher scheme. Health Policy. 2010;96(2):98-107.

8. Powell-jackson T, Morrison J, Tiwari S, Neupane BD, Costello AM. The experiences of districts in implementing a national incentive programme to promote safe delivery in Nepal. BMC Health Services Research. 2009;11:1-11.

9. Lim SS, Dandona L, Hoisington JA, James SL, Hogan MC, Gokidou E. India's Janani Suraksha Yojana, a conditional cash transfer programme to increase births in health facilities: an impact evaluation. Lancet. 2010;375:2009-20.

10. Vikram K, Sharma AK, Kannan AT. Beneficiary level factors influencing Janani Suraksha Yojana utilization in urban slum population of trans-Yamuna area of Delhi. The Indian Journal of Medical Research. 2013;138(3):340-6.

11. Panja TK, Mukhopadhyay DK, Sinha N, Saren AB, Sinhababu A, Biswas AB. Are institutional deliveries promoted by Janani Suraksha Yojana in a district of West Bengal, India?. Indian J Public Health. 2012;56:69-72.

12. Lanjewar S, Chaudhary S, Kubde S, Bhatkule P. Evaluation of Janani Suraksha Yojna (JSY) and Universal Immunization Programme (UIP) in two districts of Maharashtra. Int J Sci Res. 2013;2:97-9.

13. Vishwanath WH, Jatti GM, Tannu U. Missed opportunities of Janani Suraksha Yojana benefits among the beneficiaries in slum areas. Natl $\mathbf{J}$ Community Med. 2011;2:40-2.

14. Malik JS, Kalhan M, Punia A, Sachdeva S, Behera BK. Utilization of health services under Janani Suraksha Yojna in rural Haryana 2013. Int J Med Public Health. 2013;3:176-9.

15. Malini S, Tripathi RM, Khattar P, Nair KS, Thekre YL, Dhar N, et al. A rapid appraisal of functioning of Janani Suraksha Yojana in South Orissa. Health Popul Perspect Issues. 2008;31:126-31.

16. Singh HS, Tamulee P. International Journal of Scientific and Research Publications. 2010;2.

Cite this article as: Goel S, Sharma D, Rani S. Factors influencing Janani Suraksha Yojana utilization in a northern city of India. Int J Reprod Contracept Obstet Gynecol 2017;6:575-9. 